\title{
Influence of external loads to wind turbine tower
}

\author{
Nejra Isic ${ }^{1}$, Marin Petrovic ${ }^{{ }^{*}}$ \\ ${ }^{1}$ Mechanical Engineering Faculty, University of Sarajevo, Bosnia
}

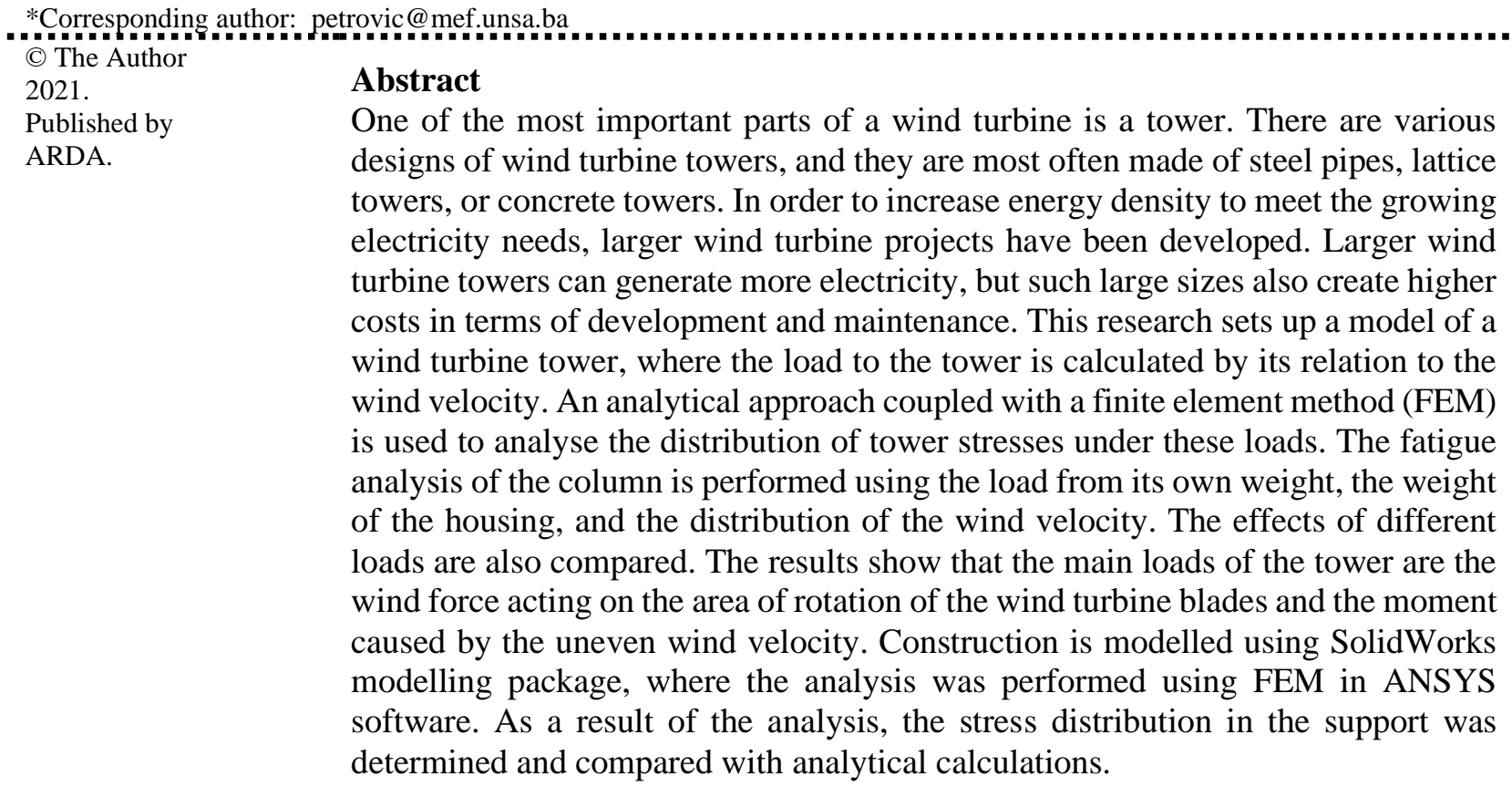

Keywords: Wind turbine; tower; wind; load; FEM

\section{Introduction}

\subsection{Use of word-processing software}

Wind turbines convert energy from wind into electricity by rotating propeller-like blades around a rotor. The rotor rotates a drive shaft, which then rotates an electric generator. Three key factors affect the amount of energy the turbine can use from wind: wind velocity, air density and displacement range. The denser the air, the more energy the turbine receives.

Analysis of wind energy data shows that in the last 10 years it has been promoted to the fastest growing branch of industry in the world, and to one of the renewable energy sources that every serious electricity network must count on in its system.

Although there are many more advantages of wind energy and they are more obvious than disadvantages, the greatest disadvantage is that the entire process of using wind energy depends on an unpredictable constant, a presence of wind in a selected area. The main advantages include unlimited, free renewable resource (wind itself), economic value, maintenance costs and the location of the wind collection plant. First and foremost, wind is an unlimited, free, renewable resource. Wind is a natural phenomenon and the collection of wind kinetic energy in no way affects wind currents or cycles. Gathering wind power is a clean, non-polluting way to generate electricity. Unlike other types of power plants, it does not emit air pollutants or greenhouse gases.

After the rotor, a tower is the most massive and largest part of the wind turbine. The value of towers and foundations as part of the construction components of wind turbines is often underestimated, while the stability of the wind turbine is the first feature that needs to be proven in order to obtain a permit to build it. The tower

This work is licensed under a Creative Commons Attribution License (https://creativecommons.org/licenses/by/4.0/) that allows others to share and adapt the material for any purpose (even commercially), in any medium with an acknowledgement of the work's authorship and initial publication in this journal. 
is important for both the static stability of the wind turbine and the dynamic behaviour. Therefore, it is necessary to perform a detailed analysis of the construction of the tower and the foundation.

In addition to carrying the housing and the rotor, the basic task of the tower is to take all the loads during operation and transfer them to the foundation, including the load during the installation of the turbine rotor. Wind turbine towers are most often made of steel, while a reinforced concrete version can be seen less often. As a rule, it is of tubular design and electrical installations are placed inside it, the twisting of which is controlled electronically.

In this paper, attention is paid to the method of construction of wind turbine towers and a detailed analysis of the loads to which the column is exposed.

\section{Location of wind velocities}

Wind velocity is the basic factor from which to start designing all wind turbines that will be located in a selected area, their number and spatial distribution. Wind velocity also serves as a starting point for all calculations of economic viability and energy production. The average annual wind velocity at a certain height above the ground is its most important characteristic. The wind generator starts when the wind velocity rises above approximately $3 \mathrm{~m} / \mathrm{s}$. At this velocity, the production of electricity is very small, but with increasing velocity, the amount of electricity produced increases to a maximum, which is achieved at a wind velocity of about 12 $\mathrm{m} / \mathrm{s}$. With a further increase in wind velocity, the amount of energy produced no longer increases. When the wind velocity rises above 25 to $30 \mathrm{~m} / \mathrm{s}$, the wind turbine shuts down. Large fluctuations in wind velocity on an annual basis are by no means favourable for wind exploitation. Thus, the annual average can contain a large number of hours with a velocity above $30 \mathrm{~m} / \mathrm{s}$ or below $3 \mathrm{~m} / \mathrm{s}$, which is completely unfavourable. The optimal wind for energy utilization is wind up to medium strength, without large oscillations and with the highest possible frequency [1].

Taking these guidelines into account, mountainous region with highest average wind velocities in Bosnia and Herzegovina, which is region of Bjelašnica mountain, was chosen in this analysis. Wind velocities in this locality are within the range of $5.3 \mathrm{~m} / \mathrm{s}(\mathrm{E})$ to $12 \mathrm{~m} / \mathrm{s}(\mathrm{S})$. North wind (N) in January has the average velocity of $10.5 \mathrm{~m} / \mathrm{s}$. Based on the data and research conducted, a wind rose given in Fig. 1 was used to analyse the wind turbine tower at Bjelašnica site. This area was chosen because it has sufficient wind velocity throughout the year for maximum energy utilization.

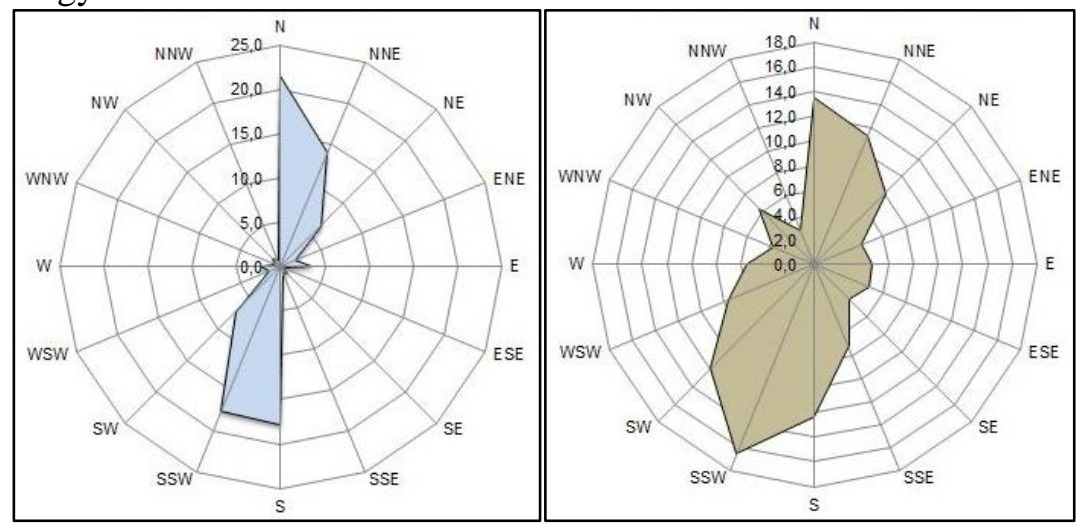

Figure 1. Wind rose for Bjelašnica

\section{Analytical solution}

\subsection{Introduction}

In recent years, the need for wind turbines of increasing dimensions has been growing, and with that the construction loads of wind turbines are becoming more and more significant and cannot be ignored. The main cause of the load on the wind turbine structure is the wind. In fact, of the total wind energy, only a portion is converted into a buoyancy force component that causes the rotor to rotate while a large portion of the wind energy is converted into a force component that causes the blade to thrust. The thrust force is added to the drag force acting when the air flows over the blades. In addition to the force of thrust on the blades, which acts in the direction of the wind, there are also forces and moments along the other two axes. The forces and moments on 
each blade add up and load the rest of the structure. As the hub and blades rotate, the rest of the structure rests. Thus, the loads of most wind turbine components are due to the load of the wind turbine blades.

Non-alloy structural grade steel S355 $\mathrm{J} 2+\mathrm{N}$, which is widely used in engineering and construction industries, was selected as the material for the tower mantle. This steel has a density of $\rho_{s}=7,600 \mathrm{~kg} / \mathrm{m}^{3}$ and a yield strength $\sigma_{y}=240 \mathrm{MPa}$.

The basic loads to which the mechanical resistance and stability of the wind turbine are proven are divided into:

- constant loads, which include the own weight of the structure and additional continuous action and

- variable load - wind action.

In this analysis, such coordinate system will be used in which the $x$-axis is located in the direction of the longitudinal axis of the column, the $z$-axis in the wind direction, while the $y$-axis is placed perpendicular to the other two axes to form the right Cartesian coordinate system.

\subsection{Constant loads}

The replacement weight of the load-bearing elements of the structure is determined based on dimensions of elements and a specific weights of the materials from which these elements are made [2,3]. For a more detailed calculation of the tower, the following parameters were adopted: the standard rotor with a diameter of $R=145$ $\mathrm{m}$, a blade surface of $A_{b}=548.04 \mathrm{~m}^{2}$ and a mass of $m_{r}=74.5 \mathrm{t}$, as well as the housing of mass $m_{h}=44.5 \mathrm{t}$. The rotor and the housing exert pressure on the top of the tower, which in this case amounts to $G_{r+h}=1,167.72 \mathrm{kN}$. An additional constant load that affects the stability of the structure, according to DIN 4131, is the ice load. The ice load is concentrated on the blades and the wind turbine housing, as well as on the rear third of the column height. The average icing of the structure is $d_{i}=3 \mathrm{~cm}$ and the specific weight of ice is $\gamma_{i}=8 \mathrm{kN} / \mathrm{m}^{3}$. The ice load on the wind turbine column $G_{i}$ was taken as $15 \%$ of the concentrated load (weight $G_{r+h}$ ). In the further calculation, the load from the weight of the rotor, housing and ice will be considered as a continuous load amounting to:

$$
G_{c}=G_{r+h}+G_{i}=1.15 G_{r+h}=1,342.88 \mathrm{kN}
$$

In addition to the rotor and the housing, the constant load is also own weight of the tower $G_{t}$ which depends on its dimensions, which will be determined depending on the load so as to satisfy the allowable stresses (yield strength) of the selected tower manufacturing material. Normal and shear stresses occur in the tower due to external forces. Exposure of the structure to wind causes bending and shear.

Normal stress is made up of the fixed and the variable part. The fixed part of the normal stress is the compression stress $\sigma_{p}$ which occurs due to the constant load of the structure from the rotor and the housing, the weight of ice and tower's own weight:

$$
\sigma_{p}=\left(G_{c}+G_{t}\right) / A
$$

where $A=\left(D^{2}-d^{2}\right) / 4$ is cross section area of the tower. Based on experience, diameter ratios were adopted:

$$
D / d=1.044 \quad \text { and } \quad D / D^{\prime}=d / d^{\prime}=1.18
$$

Where $D$ outer diameter at the bottom of the tower, $d$ inner diameter at the bottom of the tower, $D$ ' outer diameter at the top of the tower i $d$ ' inner diameter at the top of the tower. Taking into account previous relations, the cross-sectional area of the tower now amounts to:

$$
A=0.0825 D^{3} \pi / 4
$$

In order to calculate compression stress $\sigma_{p}$, it is necessary to determine own weight of the tower according to the following formula:

$$
G_{t}=m g=\rho_{s} g V
$$

Since the tower is a truncated hollow cone, its volume is calculated as: 


$$
V=V_{1}-V_{2}
$$

where $V_{1}$ and $V_{2}$ are volumes of full and hollow part of the tower, determined as:

$$
\begin{aligned}
& V_{1}=\frac{\pi}{2} h\left[\left(\frac{D}{2}\right)^{2}+\frac{D}{2} \frac{D^{\prime}}{2}+\left(\frac{D^{\prime}}{2}\right)^{2}\right] \\
& V_{2}=\frac{\pi}{2} h\left[\left(\frac{d}{2}\right)^{2}+\frac{d}{2} \frac{d^{\prime}}{2}+\left(\frac{d^{\prime}}{2}\right)^{2}\right]
\end{aligned}
$$

When previously adopted diameter ratios given in (3) are utilized, the volume $V$ becomes:

$$
V=0.026 \pi h D^{2}
$$

Based on determined volume $V$ and cross-sectional area $A$, the compressive stress is determined as:

$$
\sigma_{p}=4 / 0.0825\left(G_{c} / \pi / D^{2}+0.026 \rho_{s} g h\right)
$$

\subsection{Wind action}

According to the data from the Hydro-meteorological Institute of FB\&H, the average maximum wind velocity on Bjelašnica for the period from 2000 to 2020 was $12.2 \mathrm{~m} / \mathrm{s}$. Since the determination of the average velocity does not include wind velocity values lasting up to 10 minutes, in order for the structure to be stable, the calculation of the stability of the structure will be calculated over the maximum velocity [4,5]. The deviation of the maximum from the mean value of the velocity is given by $F_{m}=v_{\max } / v_{0}$ which for the bare area amounts to $F_{m}=7$. Wind pressure $p$ is given by:

$$
p=\rho v_{\max }^{2}=0.613 v_{\max }^{2}
$$

where $\rho=1.226 \mathrm{~kg} / \mathrm{m}^{3}$ is an air density. The wind pressure acting on the surface of the blades causes bending of the tower whose load is manifested by the normal flexural stress $\sigma_{f}$ and the tangential shear stress $\tau$ in the critical section at the bottom of the structure [6,7]. The wind pressure can be converted into the force $F$ which becomes:

$$
F=0.613 v_{\max }^{2} A_{b}
$$

In order to determine the flexural stress $\sigma_{f}$ it is necessary to know the bending moment $M_{f}=F h$ as well as section modulus $W_{x}$ which, using former ratios given in (3), equals to $W_{x}=0.121 D^{3} \pi / 32$. Flexural stress now becomes:

$$
\sigma_{f}=32 \cdot 0.613 v_{\max }^{2} A_{b} h /\left(0.121 \pi D^{3}\right)
$$

Using (4) and (12), shear stress can be calculated according to:

$$
\tau=F / A=4 \cdot 0.613 v_{\max }^{2} A_{b} /\left(0.0825 \pi D^{2}\right)
$$

For easier and clearer calculation, introducing appropriate constants, following expressions are obtained:

$$
\sigma_{f}=A^{\prime} v_{\max }^{2} h / D^{3} ; \quad \sigma_{p}=B^{\prime} / D^{2}+C^{\prime} h ; \quad \tau=E^{\prime} v_{\max }^{2} / D^{2}
$$

where the constants are given with:

$$
A^{\prime}=16 \rho A_{b} / 0.121 / \pi ; \quad B^{\prime}=4 G_{c} / 0.0825 / \pi ; \quad C^{\prime}=4 \rho_{s} g \cdot 0.026 / 0.0825 ; \quad E^{\prime}=2 \rho A_{b} / 0.0825 / \pi
$$

The total normal stress are equal to the sum of the compressive stress and the flexural stress:

$$
\sigma=\sigma_{f}+\sigma_{p}=A^{\prime} v_{\max }^{2} h / D^{3}+B^{\prime} / D^{2}+C^{\prime} h
$$




\subsection{Tower sizing}

Analysis and sizing of the tower is performed in two different combinations:

- calculation of the tower diameter $D$ as a function of tower height $h$ for constant wind velocity $v_{\max }$,

- calculation of the tower diameter $\mathrm{D}$ as a function of wind velocity $\mathrm{v}$ for constant tower height $\mathrm{h}$.

The first combination considers maximum wind velocity of $v_{\max }=85.4 \mathrm{~m} / \mathrm{s}$, whereas the tower height was varied in the interval of $0 \leq v \leq 85.4 \mathrm{~m} / \mathrm{s}$.

When testing the stress on the theoretical case, the hypothesis of the largest specific deformation work on shape change was used, i.e. the Von Mises hypothesis:

$$
\sigma_{i}=\left(\sigma^{2}+3 \tau^{2}\right)^{1 / 2} \leq \sigma_{y}
$$

where normal and shear stresses are:

$$
\sigma=A h / D^{3}+B / D^{2}+C h \quad \text { and } \quad \tau=E / D^{2}
$$

The constants are calculated as a product of already defined constants in (16) and square of maximum velocity:

$$
A=A^{\prime} v_{\max }^{2} ; \quad B=B^{\prime} ; \quad C=C^{\prime} ; \quad E=E^{\prime} v_{\max }^{2}
$$

After inclusion of (19) and (20) in (18), the following equation is obtained:

$$
\left(\left(A h / D^{3}+B / D^{2}+C h\right)^{2}+3\left(E / D^{2}\right)^{2}\right)^{1 / 2}=\sigma_{y}
$$

Inserting appropriate values, the equation becomes:

$$
\begin{aligned}
& 44,089,343.95 h^{2} / D^{6}+9,506,013.84 h / D^{5}+4,969,903.67 / D^{4}+ \\
& +40,164.79 h^{2} / D^{3}+4,329.92 h / D^{2}+9.15 h^{2}=5.76 \cdot 10^{7}
\end{aligned}
$$

The solution (22) is presented in Fig. 2. It is clear that the change in the diameter of the wind turbine tower as a function of the tower height, for a certain constant velocity, has an almost linear character. It can also be noticed that, increasing the velocity, the diameter of the wind turbine tower increases more intensively with the height. The difference between the diameters for the initial height of $90 \mathrm{~m}$ and the maximum analysed height of $150 \mathrm{~m}$ at the minimum velocity of $20 \mathrm{~m} / \mathrm{s}$ is only $0.31 \mathrm{~m}$, while at the maximum velocity of $85.4 \mathrm{~m} / \mathrm{s}$ this difference equals to $0.84 \mathrm{~m}$.

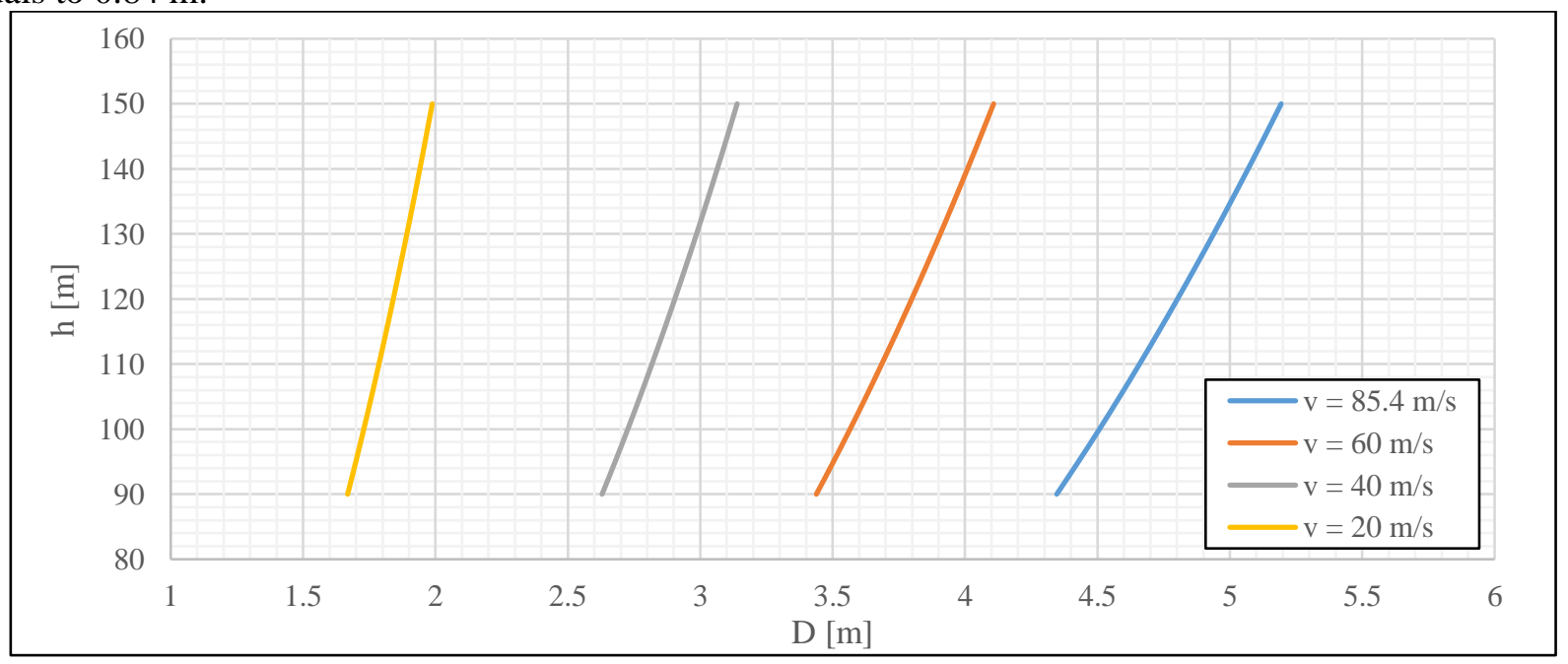

Figure 2. Tower diameter as a function of height

For the second combination, previously determined tower height of $h=120 \mathrm{~m}$ was taken for the analysis, whereas wind velocity was varied in the interval of $0 \leq v \leq 85.4 \mathrm{~m} / \mathrm{s}$. Using previously derived expressions for stresses, in this case the equation becomes: 


$$
11.94 v^{4} / D^{6}+156.41 v^{2} / D^{5}+512.39 / D^{4}+79.3 v^{2} / D^{3}+519.59 / D^{2}+131.72=5,760
$$

The solution (23) is presented in Fig. 3. It is clear that the change in the diameter of the wind turbine tower as a function of wind velocity, for a certain constant tower height, has a parabolic character. It can also be noticed that, increasing the height, the diameter of the wind turbine tower increases more intensively with the velocity.

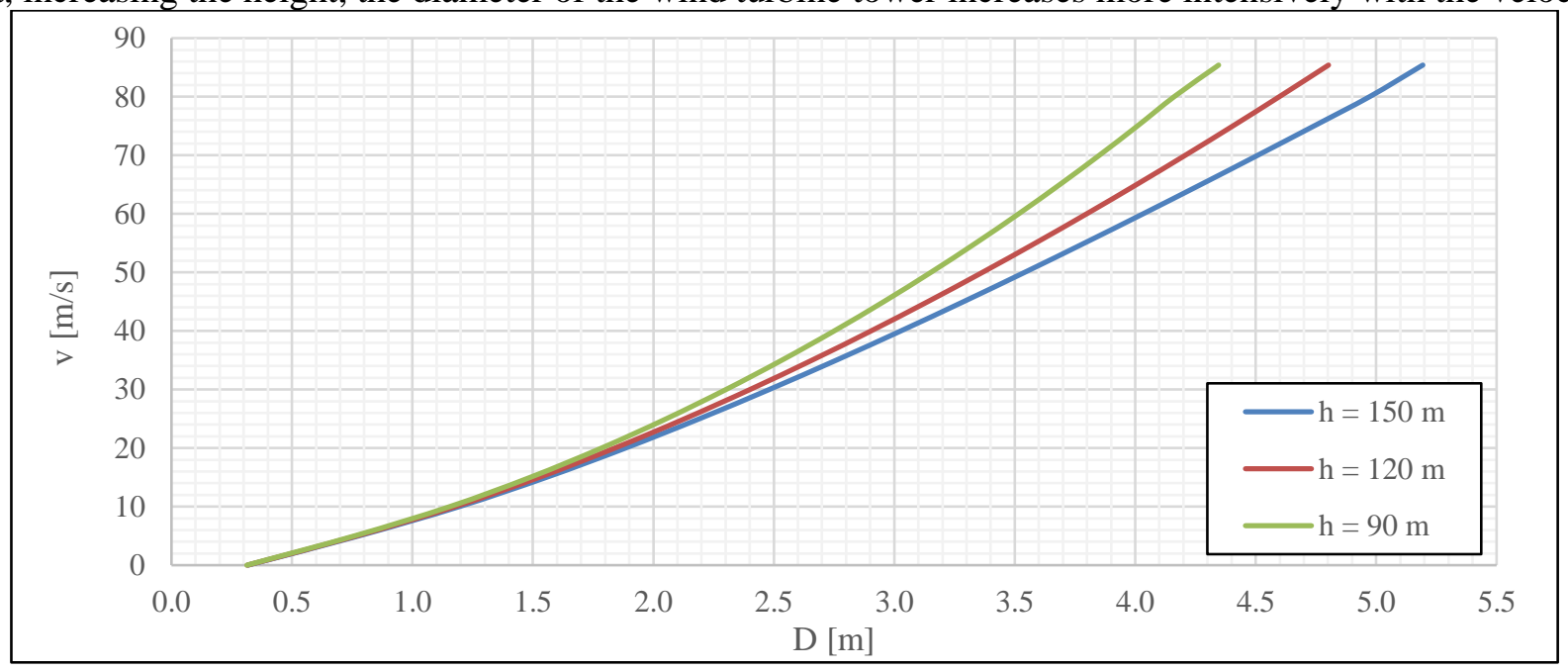

Figure 3. Tower diameter as a function of wind velocity

After the analysis of all obtained analytical calculations for the tower of height $h=120 \mathrm{~m}$ at the maximum wind velocity, the values of the tower diameters to be used for numerical analysis were determined. They are given in Table 1.

Table 1. Tower diameters used for further analysis

\begin{tabular}{cc}
\hline Parameter & Value $(\mathrm{m})$ \\
\hline$D$ & 4.80 \\
$d$ & 4.60 \\
$D^{\prime}$ & 4.07 \\
$d^{\prime}$ & 3.90 \\
\hline
\end{tabular}

\section{Numerical simulation}

Wind turbine modelling was performed using the SolidWorks software package, while displacement and stress analysis was done in the ANSYS program. The mesh used in the analysis is shown in Fig. 4.

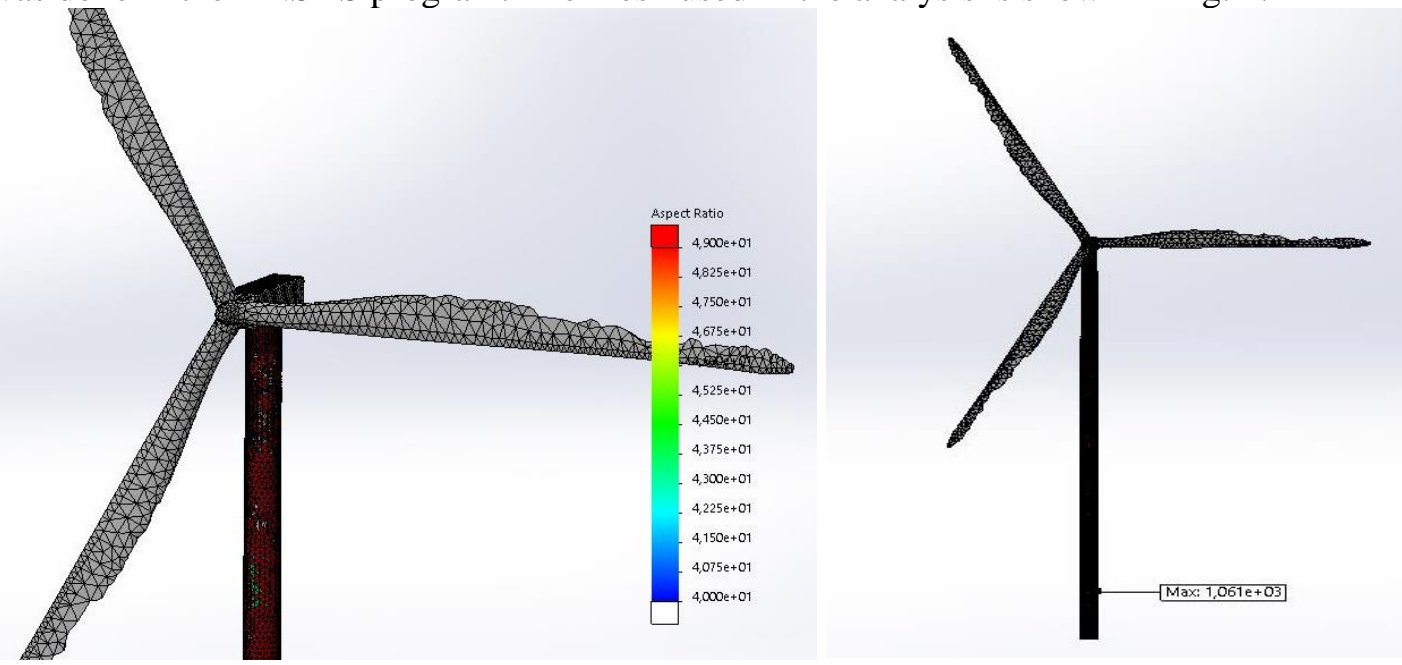

Figure 4. FEA mesh 
Aluminium is the default material for the housing and blades, while steel S355 $\mathrm{J} 2+\mathrm{N}$ was chosen as the material of the tower. The connections between the tower and the housing are strong since the joint is made by welding. Weight and wind loads are presented in Fig. 5.
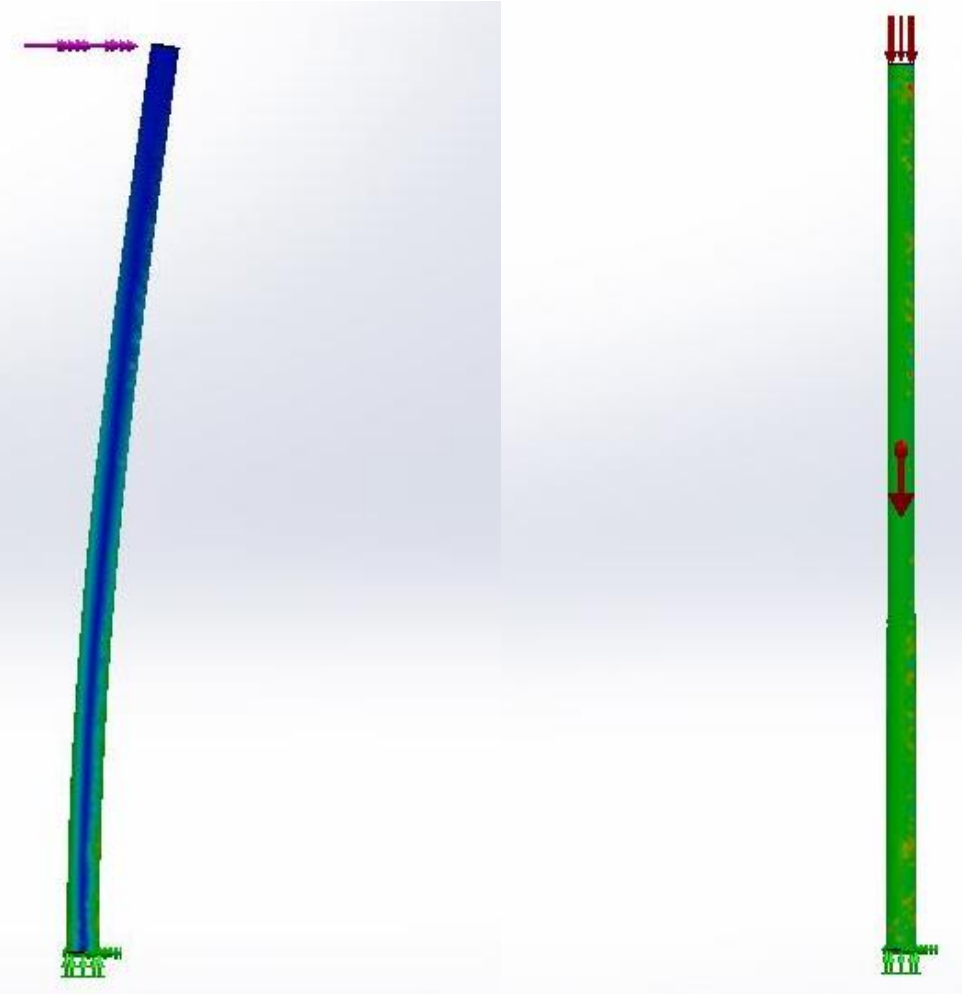

Figure 5. Defined forces: wind force on tower (left) and parts weights (right)

Stress values due to the action of all loads are shown in Fig. 6.

Model name:Stub vjetrenjace tezina

Study name:Kombin adja 2(-Default-)
Plot type: Static nodal stress Stress 1

Plot type: Static no dal stress
Deformation scale: 131,079
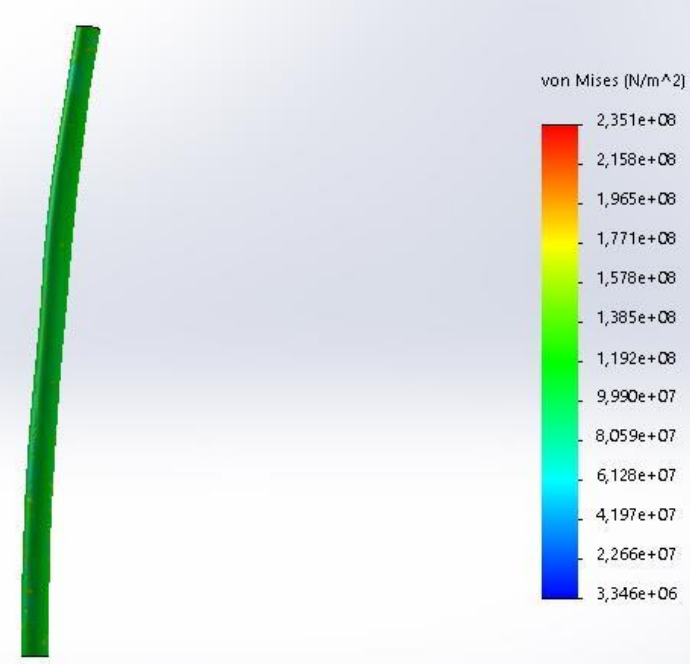

Figure 6. Stresses in wind turbine tower

The greatest stresses occur at the bottom of the tower on the opposite side from the action of the wind, which is expected because this part is located furthest from the rotor of the wind turbine. The maximum stress in the critical cross section is shown in Fig. 7. 


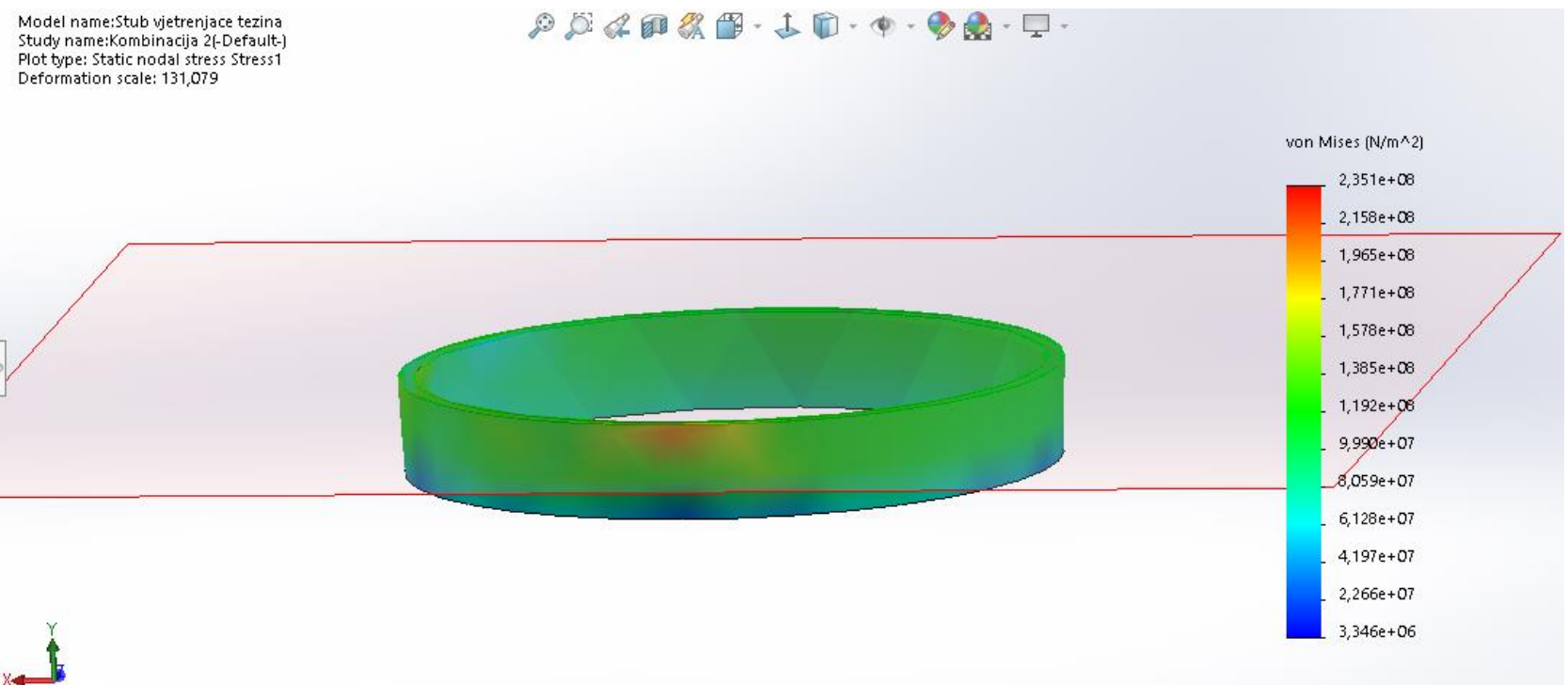

Figure 7. Magnitude and position of maximum stress

\section{Discussion}

Under the action of wind and pressure, the maximum stress obtained analytically is $240 \mathrm{MPa}$. The stress obtained by FEM analysis at the junction of the rear support and the support where the collector is located is $235.1 \mathrm{MPa}$. This discrepancy of $2.04 \%$ shows a good agreement between analytical and numerical calculations. Also, the place of occurrence of the highest load coincides in the analytical and numerical calculation, with the provision that in the analytical calculation this stress is obtained at one point, and in the numerical calculation in one finite element.

\section{Conclusions}

The load-bearing structure (tower) as a basic part of the wind turbine is exposed to external loads and significantly affects the stability of the structure and the amount of investment. External loads have to be described as accurately as possible and predicted so that unwanted consequences do not occur during the operation of the system. Also, the effect of ice on the structure must be taken into account, due to which an additional load on the load-bearing structure occurs in the winter.

Here, a theoretical quasi-static calculation of the wind turbine tower structure was performed. Wind forces and the own weight of the structure were calculated. Since the materials used for the construction were adopted, the stresses obtained were compared with the yield strength using hypothesis of the largest specific deformation work on shape change. For the theoretical construction, the optimal diameters of the wind turbine tower were found according to bearing capacity and economy (material consumption). The optimization of the tower dimensions was performed for certain heights at the maximum wind velocity (extreme conditions).

After the analytical calculation, the wind turbine was modelled and the load calculation of the wind turbine tower was performed by the finite element method in the ANSYS software package. The locations of the highest stresses are the same as in the analytical calculation, and the deviations of the values are insignificant. This confirms the adequacy of the approximations used in the analytical calculation when converted to linear loads. Based on the verification of the results of the analytical and numerical calculation of the wind turbine tower load, it can be concluded that the dimensions of the wind turbine tower obtained by the analytical calculation meet the prescribed load-bearing capacity and stability criteria. This shows that the analytical results can be used to obtain accurate results based on which the tower can be constructed.

\section{References}

[1] Y. Hsu, W.F. Wu and Y.C. Chang, "Reliability Analysis of Wind Turbine Towers", Procedia Engineering, vol. 79, pp. 218-224, 2014.

[2] P. Brøndsted, H. Lilholt and A. Lystrup, "Composite Materials for Wind Power Turbine Blades", Annual Review of Materials Research, vol. 35, pp. 505-538, 2005. 
[3] L. Mishnaevsky Jr, K. Branner, H.N. Petersen, J. Beauson, M. McGugan and B.F. Sørensen, "Materials for Wind Turbine Blades: An Overview", Materials, vol. 10, pp. 1285-1308, 2017.

[4] J.N. Sørensen, "Aerodynamic Aspects of Wind Energy Conversion", Annual Review of Fluid Mechanics, vol. 43, pp. 427-448, 2011.

[5] X. Chen, J. Li and J.J. Chen, "Wind-induced response analysis of a wind turbine tower including the blade-tower coupling effect", Journal of Zhejiang University-SCIENCE A, vol. 10, pp. 1573-1580, 2009.

[6] N. Kim and J.W. Jin, "Sensitivity analysis of offshore wind turbine tower caused by the external force", KSCE Journal of Civil Engineering, vol. 17, pp. 859-864, 2013.

[7] Y. Xu, W.L. Sun and J.P. Zhou, "Static and dynamic analysis of wind turbine tower structure", Advanced Materials Research, vol. 33, pp. 1169-1174, 2008. 